\title{
Analysis of Interleukin 17A in periapical abscess and granuloma lesions
}

\section{Luciana Gonçalves Valente FERREIRA \\ Flávia Cristina Perillo ROSIN Luciana CORRÊA}

Universidade de São Paulo - USP, School of Dentistry, Department Stomatology, São Paulo, SP, Brazil.
Declaration of Interests: The authors certify that they have no commercial or associative interest that represents a conflict of interest in connection with the manuscript.

\section{Corresponding Author:}

Luciana Corrêa

E-mail: lcorrea@usp.br

DOI: 10.1590/1807-3107BOR-2016.vol30.0034

Submitted: Mar 18, 2015

Accepted for publication: Aug 26, 2015

Last revision: Nov 17, 2015
Abstract: Interleukin 17A (IL-17A) is a proinflammatory cytokine responsible for the initiation and propagation of inflammation. One of its actions is the recruitment of neutrophils to the site of infection. The aim of this study was to investigate whether there is association between IL-17A expression and neutrophil infiltration in periapical abscesses and periapical granulomas, as well as to find which type of Tlymphocyte effector $\left(\mathrm{CD}^{+}\right.$or $\left.\mathrm{CD} 8^{+}\right)$expresses IL-17A in these lesions. Elastase, CD4, CD8, and IL-17A were analyzed by immunohistochemistry and immunofluorescence, in the biopsies of periapical lesions. Abscess lesions exhibited the highest labeling area for IL-17A $(p=0.011)$. During double immunofluorescence staining, there were significantly more $\mathrm{CD} 4^{+} / \mathrm{IL}^{-17 \mathrm{~A}^{+}}$cells compared to $\mathrm{CD} 8^{+} / \mathrm{IL}^{-17 \mathrm{~A}^{+}}$cells, both in the abscesses $(p=0.025)$ and granulomas $(p=0.011)$. In conclusion, IL-17A was intensively expressed in periapical abscesses rich in neutrophils. The high percentage of IL-17A in these cases suggests the participation of this cytokine particularly in the acute stages of the inflammatory process of the periapical lesions.

Keywords: Interleukin-17; Periapical Abscess; Periapical Granuloma.

\section{Introduction}

Abscess and granuloma lesions frequently occur in the dental periradicular region due to pulpal and periodontal infection. ${ }^{1}$ Abscesses are associated with acute clinical signs and symptoms such as pain, suppurative exudation, and swelling; whereas, granuloma is considered a chronic asymptomatic lesion, although sporadic acute episodes associated with secondary infections have been reported., ${ }^{1,2}$ Histopathologically, periapical acute abscesses are characterized by an intense, localized neutrophil and macrophage infiltration, diffused in a necrotic matrix surrounded by a fibrous connective tissue, ${ }^{1}$ lymphocytes and mast cells can be observed, but they occur in low numbers. On the other hand, periapical granulomas exhibit an intense, localized mononuclear infiltrate consisting of lymphocytes and plasma cells diffused in a fibrous connective tissue containing numerous fibroblasts and vessels. ${ }^{3,4}$ Focal areas of intense neutrophil infiltrate in the granulation tissue can be observed sometimes in cases of granulomas with acute exacerbation. ${ }^{1}$ The immune response in periapical lesions is frequently investigated to understand the relationship between the pathogenesis of these lesions and the microbiota, and why some lesions are refractory to endodontic treatment. ${ }^{3}$ 
A new class of immune response related to $\mathrm{T}$ helper lymphocytes has recently been described to explain the various immune reactions observed in inflammatory diseases. ${ }^{5}$ This class is named Th17 and is associated with various cytokines, mainly Interleukin 17A and 22. ${ }^{6}$ Interleukin 17A (IL-17A) is a member of the IL-17 cytokine family, which is associated with the initiation and propagation of inflammatory stimuli in several diseases, such as rheumatoid arthritis, psoriasis, multiple sclerosis, ${ }^{5}$ and periodontal disease. ${ }^{6}$ This cytokine is produced by multiple defense cells, mainly $\mathrm{CD}^{+}$and $\mathrm{CD} 8^{+}, 7$ and exhibits a proinflammatory effect that causes the release of other cytokines and chemokines. ${ }^{8}$ The release of IL-6, G-CSF, and CXCL2 induced by IL-17A can act on granulocytopoiesis, leading to the proliferation, maturation, and migration of neutrophils. ${ }^{8,9}$

Some studies have investigated the Th17 phenotype in periapical cysts and granulomas. ${ }^{4,10,11,12}$ An association between neutrophil infiltrate and IL-17A expression has been partially detected in symptomatic periapical granulomas. ${ }^{4}$ but IL-17A expression is not known to occur in periapical abscesses. The aim of this study was to investigate IL-17A immunolabeling expression in periapical abscesses and granulomas and determine which type of $\mathrm{T}$ helper lymphocytes $\left(\mathrm{CD}^{+}\right.$or $\left.\mathrm{CD}^{+}\right)$expresses IL-17A in these lesions.

\section{Methodology}

This study was approved by our institution's Ethics Committee on Human Research (Process \#206.324).

\section{Biopsies selection}

Between 2010 and 2013, 60 cases of periapical abscess and 114 cases of periapical granuloma were diagnosed by the histopathology service of our institution. From this period, 35 records of periapical abscess cases and 35 of periapical chronic inflammatory processes (periapical granulomas) were selected from the archives of this service. Only the cases with histopathological characteristics of acute periapical abscesses were included in the study. The histopathological criteria for determining the diagnosis of acute periapical abscesses were the presence of predominant neutrophil infiltrate in a necrotic matrix, with few chronic inflammatory cells and discrete granulation tissue. Signs of suppuration and the reporting of pain described in the patients' records contributed to this definitive histopathological diagnosis. Cases with the diagnosis of chronic apical abscess were excluded (i.e., those with a high frequency of mononuclear cells compatible with lymphocytes mixture with neutrophils, and with a great amount of mature granulation tissue and fibrosis). The histopathological criteria for determining the diagnosis of periapical granuloma were the presence of predominant chronic inflammatory cell infiltrate, mainly macrophages and lymphocytes, as well as the presence of granulation tissue, rich in vascular vessels and fibroblasts. Cases with doubtful histopathological aspect were excluded. Cases without the clinical diagnosis of apical periodontitis or those without the clinical description that indicated the presence of the lesion in the periapical site were also excluded.

Some of the selected cases were not submitted to immunolabeling analyses due to the paucity of paraffin-embedded material. In the end, 25 cases of abscesses and 28 cases of granulomas were included. Ten histological sections ( $3 \mu \mathrm{m}$ thick) of each case were then cut using a rotary microtome (Olympus Cut 4060, Tokyo, Japan). The slices were stretched onto 3-aminopropyltriethoxysilane-treated glass slides and maintained at $60^{\circ} \mathrm{C}$ for 24 hours. Analyses were then performed using immunohistochemical and immunofluorescence techniques as follows.

\section{Immunohistochemical analysis}

Eight histological sections of each case were used to perform immunohistochemical tests. All cases were submitted to immunohistochemical reaction using four primary antibodies (two slices for each): anti-elastase (NP 57 clone, 1:50 dilution, Dako $^{\circledR}$, Carpenteria, USA), anti-CD4 (10B5 clone, 1:50 dilution, Abcam Inc., Cambridge, USA), anti-CD8 (C8/144B clone, 1:50 dilution, Dako ${ }^{\circledR}$ ), and anti-IL-17A (polyclonal, 1:100 dilution, Abcam). Before incubation, the histological sections were dewaxed and rehydrated in xylol and in descending grades of ethanol solution, respectively. Antigen retrieval was performed for CD4, CD8, and IL-17A using citrate ( $4 \mathrm{mM}), \mathrm{pH} 6.0$, in a water bath at $97^{\circ} \mathrm{C}$ for 40 minutes. Antigen retrieval was not 
performed for elastase, because the manufacturer of this antibody does not recommend this procedure due to the possibility of granule degradation. Endogenous peroxidase was inhibited by treatment with $\mathrm{H}_{2} \mathrm{O}_{2}$ $20 \% \mathrm{v} / \mathrm{v}$ in methanol (1:1) for $30 \mathrm{~min}$ at room temperature for 60 minutes. Non-specific binding was avoided by blockage using $1 \%$ bovine serum albumin diluted in PBS (30 min incubation at room temperature). Primary antibodies were then incubated at room temperature for 60 minutes. Thereafter, the samples were incubated with a biotinylated swine-antirabbit/goat/mouse antibody and a streptavidin-biotin peroxidase conjugate (LSAB System, Dako ${ }^{\circledR}$ ) for 30 min each. The reaction was then revealed by diaminobenzidine (DAB) $\left(\mathrm{Dako}^{\circledR}\right)$. The sections were then stained with Mayer's hematoxylin, dehydrated in a series of increasing grades of ethanol solution, immersed in xylol, and mounted in resin for conventional light microscopy. For the negative control, sections were incubated in a buffer without a primary antibody. Sections of human palatine tonsil were used as a positive control for all the antibodies.

\section{Double staining by immunofluorescence}

Ten cases of abscesses and granulomas with intense IL-17A immunohistochemical labeling each were subjected to CD4/IL-17A or CD8/IL-17A double immunofluorescence staining. In a pilot project, we observed that in cases with scarce or diffuse labeling for IL-17A, it was difficult to interpret the double staining. We therefore previously selected the cases with intense IL-17A expression, i.e., ten of those that exhibited the highest percentage of IL-17A labeling area obtained in the immunohistochemistry quantitation (see "Quantitative analysis" section below). We also did not perform double staining with elastase and IL-17A because the expression of elastase in the extracellular matrix did not allow a clear interpretation of the double staining due to an intense background.

The technical procedure, including the antigen retrieval, was the same as the one performed in the immunohistochemistry analysis, up to primary antibody incubation. Before the incubation, a blockage was performed for $30 \mathrm{~min}$ with $10 \%$ horse serum diluted in PBS buffer. The first incubation was performed with the CD4 or CD8 primary antibodies used in the immunohistochemistry procedure (1:50 dilution) for $1.5 \mathrm{~h}$ at room temperature. Incubation with a secondary antibody containing Texas Red ${ }^{\circledR}$ fluorochrome (TI-2000, Vector Laboratories, Burlingame, USA) was performed in a dark chamber for 1.5 hour. Thereafter, the slices were subjected to a second blockage with $10 \%$ horse serum for $30 \mathrm{~min}$, followed by incubation with the IL-17A primary antibody used in the immunohistochemistry procedure (1:100 dilution, $1.5 \mathrm{~h}$ at room temperature in a dark chamber). A second secondary antibody containing fluorescein isothiocyanate (FITC) (FI-2000, Vector Laboratories) was then incubated for $30 \mathrm{~min}$ at room temperature. Afterward, the slices were covered with a laminula fixed with a mounting medium that contained 4',6-diamidino-2-phenylindole (DAPI) fluorescent dye (Vectashield ${ }^{\circledR}$, Vector Laboratories). The fluorescence microscope (AxioImager A1, Carl Zeiss, Oberkochen, Germany) was used for observation of the slides. An image processing software program (AxioVisio 4.8 version, Carl Zeiss, Oberkochen, Germany) was used to superimpose Texas Red fluorescence spectra (red) with FITC fluorescence spectra (green), generating a double staining image (variation from yellow to orange).

\section{Quantitative analysis}

The labeling area stained by the DAB in the immunohistochemistry procedure was measured using a method adapted from a validated protocol. ${ }^{13}$ This method is based on the principle of RGB color deconvolution and uses a NIH-ImageJ plugin..${ }^{14} \mathrm{Six}$ fields, at $400 \times$ original magnification of each slice (four slices of each case for abscess and granuloma), were digitized and transferred to NIH-ImageJ software. Regions of interest were determined by one operator in a blinded manner (without knowledge of the lesion). Color deconvolution was used to separate the hematoxylin stain (blue color) from the DAB stain (brown color). The area of all the inflammatory cells was calculated by a blue color selection on the grayscale histogram, and the area of positive cells was determined by a brown color selection. The brown labeling area was then divided by the area of the inflammatory cells and multiplied by 100 . 
Cells exhibiting double staining in the immunofluorescence procedure were manually counted in six fields at $400 \times$ original magnification. Four slices of each abscess and granuloma cases were counted. The number of double staining cells were then divided by the total number of cells and multiplied by 100 .

\section{Statistical analysis}

For frequencies of clinical data, the Fisher's exact test was used in the comparison between abscesses and granulomas. Percentages of the immunohistochemical labeling area and percentages of the double immunostaining cells are presented as mean, median, interquartile range $\left(25^{\text {th }}-75^{\text {th }}\right.$ percentile), and minimum and maximum values. Friedman's and Mann-Whitney's tests were performed for the comparison between the markers and between the abscess and granuloma lesions. The level of significance was $5 \%$.

\section{Results}

\section{Clinical data}

Comparing the two lesions, there were no statistically significant differences in the clinical data. The most affected teeth were the maxillary premolars and molars (36.0\% for abscess and $35.7 \%$ for granulomas), followed by mandibular premolars and molars (28.0\% for abscess and $21.4 \%$ for granulomas) and maxillary canines and incisors ( $25.0 \%$ for abscesses and $24.0 \%$ for granulomas). For abscesses, there were $44.0 \%$ and $36.0 \%$ of asymptomatic and symptomatic cases, respectively (in $20.0 \%$ of cases there was no information about symptomatology). For granulomas, $54.0 \%$ were asymptomatic and $25.0 \%$ symptomatic (21.0\% of cases were without information).

\section{Quantitative analysis}

Figures 1 to 3 show the mean percentage or labeling area for each marker corresponding to the cases of abscess and granuloma. When only the abscess group was analyzed (Figure 1E), the percentage of elastase, CD8, and IL-17A were significantly higher than that of CD4 ( $p<0.001$ for all paired comparisons). When only the granuloma group was analyzed (Figure 2E), the percentage of CD4 labeling area was the highest, showing significant differences when compared with elastase $(p=0.005), C D 8(p=0.020)$, and IL-17A $(p=0.021)$.

When the abscess cases were compared with the granuloma cases (Figure 3), the percentages for elastase $(p<0.001)$, IL-17A ( $p=0.011)$, and CD8 $(p=0.004)$ were significantly higher in the abscess group; the granuloma lesions exhibited the highest percentage of CD4 ( $p<0.001)$.

The immunohistochemical pattern of each marker for abscesses and granulomas is illustrated in Figures 1 and 2. In the abscess cases (Figure 1), elastase was labeled intensively in the cytoplasm of the neutrophils, and was negative in the fibroblasts and mononuclear inflammatory cells. In the area of necrosis, the connective tissue also showed mild positivity. A similar pattern was observed for granulomas (Figure 2), but with less intensity. CD4 and CD8 were positive in lymphocytic cells, with homogenous labeling in the cytoplasm and in the plasma membrane in both lesions. IL-17A was labeled with a granular pattern in mononuclear cells with morphology compatible with that of lymphocytes. A majority of the neutrophils were also positive, but in some cases of abscess, these cells were positive with a moderate frequency.

Figure $4 \mathrm{E}$ shows the mean percentages of cells exhibiting double immunostaining detected by immunofluorescence. Both in the abscesses and granulomas, the percentage of $\mathrm{CD} 4^{+} / \mathrm{IL}^{-17 \mathrm{~A}^{+}}$cells was significantly higher than that of $\mathrm{CD} 8^{+} / \mathrm{IL}-17 \mathrm{~A}^{+}$cells. This percentage did not differ significantly between abscesses and granulomas. The double immunostaining is illustrated in Figure 4 (from " $\mathrm{A}$ " to " $\mathrm{D}$ ").

\section{Discussion}

The main hypothesis of this study was that the abscesses would exhibit more intense IL-17A expression than granulomas, due to their remarkably acute inflammatory nature. Our hypothesis was based mainly on studies that have demonstrated an important effect of IL-17 on neutrophil proliferation, maturation, and recruitment. ${ }^{8,9}$ The quantitative analysis of the labeling area performed in the present study reinforced this hypothesis.

The immunohistochemical panel for abscesses suggests the participation of innate immune response 

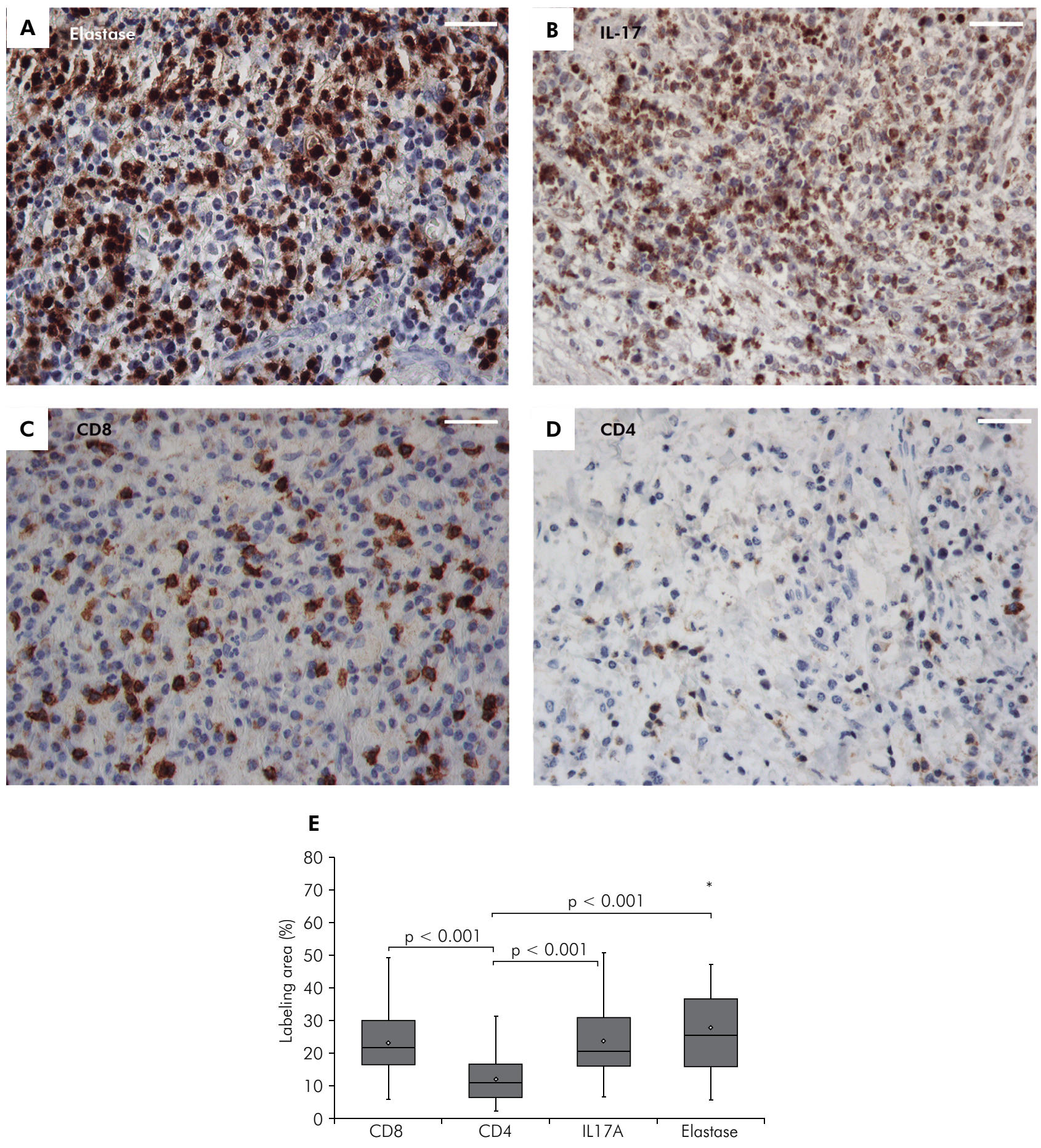

Figure 1. Immunohistochemical labeling of elastase, IL-17A, CD4, and CD8 for periapical abscesses (Streptavidin-biotin, $400 \times$ original magnification, bar $50 \mu \mathrm{m}$ ) (A) Intense immunolabeling of elastase in polymorphonucleated cells. (B) Intense IL-17A immunolabeling in inflammatory mononuclear cells and in some polymorphonucleated cells. (C) Intense CD8 immunolabeling in some mononuclear cells. (D) Moderate to intense CD4 immunolabeling in mononuclear cells. (E) Box-plot showing the percentages of elastase, IL-17A, CD8, and CD4 in periapical abscesses (bar: median; $\downarrow$ : mean; inferior line of the box: $25^{\text {th }}$ quartile; superior line of the box: $75^{\text {th }}$ quartile; whiskers: minimum and maximum values; star: outlier). $p$-value from Mann-Whitney test, statistically significant when $p<0.05$. 

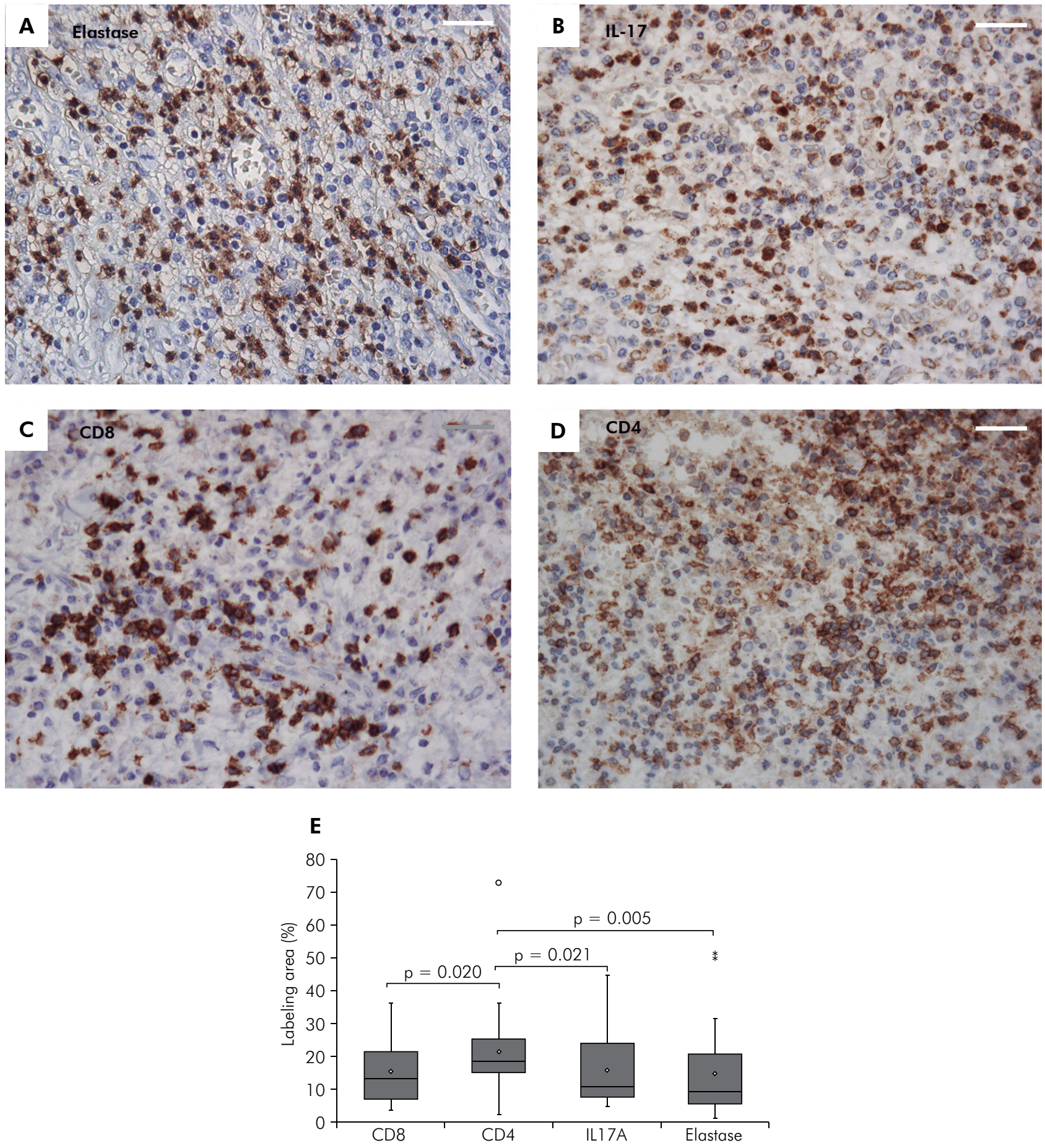

Figure 2. Immunohistochemical labeling of elastase, IL-17A, CD4, and CD8 for periapical granulomas (Streptavidin-biotin, $400 \times$ original magnification, bar $50 \mu \mathrm{m}$ ) (A) Intense IL-17A immunolabeling in polymorphonucleated cells. (B) Intense IL-17A immunolabeling present in some inflammatory mononuclear cells. (C) Intense CD8 immunolabeling in mononuclear cells, mainly plasma cells. (D) Intense CD4 immunolabeling in majority of the inflammatory mononuclear cells. (E) Box-plot showing the percentages of elastase, IL-17A, CD8, and CD4 in periapical granuloma (bar: median; $\searrow$ : mean; inferior line of the box: $25^{\text {th }}$ quartile; superior line of the box: $75^{\text {th }}$ quartile; whiskers: minimum and maximum values; star and dot: outliers). p-value from Mann-Whitney test, statistically significant when $p<0.05$. 


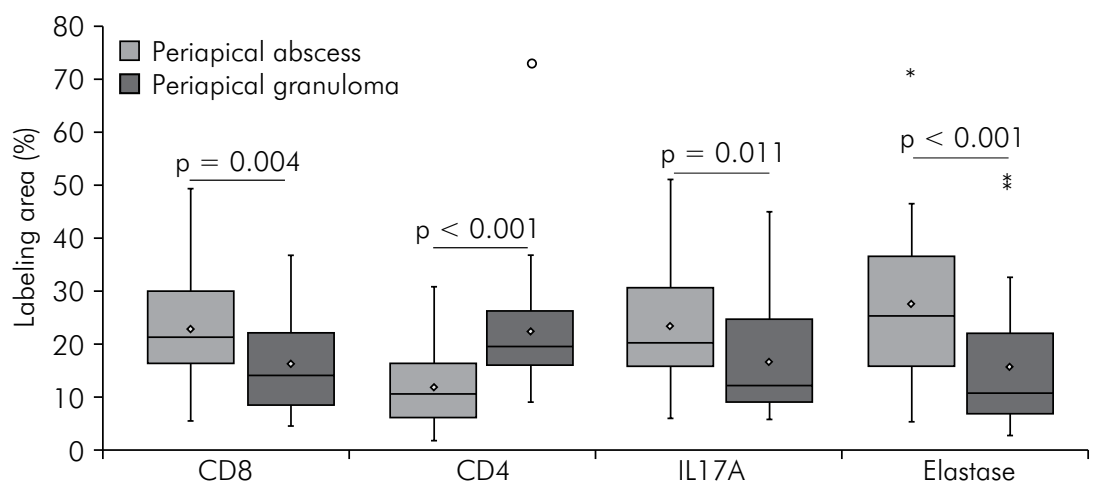

Figure 3. Box-plot graph showing the percentages of elastase, IL-17A, CD8, and CD4 in periapical abscesses versus periapical granulomas (bar: median; $\searrow$ : mean; inferior line of the box: $25^{\text {th }}$ quartile; superior line of the box: $75^{\text {th }}$ quartile; whiskers: minimum and maximum values; stars and dot: outliers). $p$-value from Mann-Whitney test, significant when $p<0.05$.
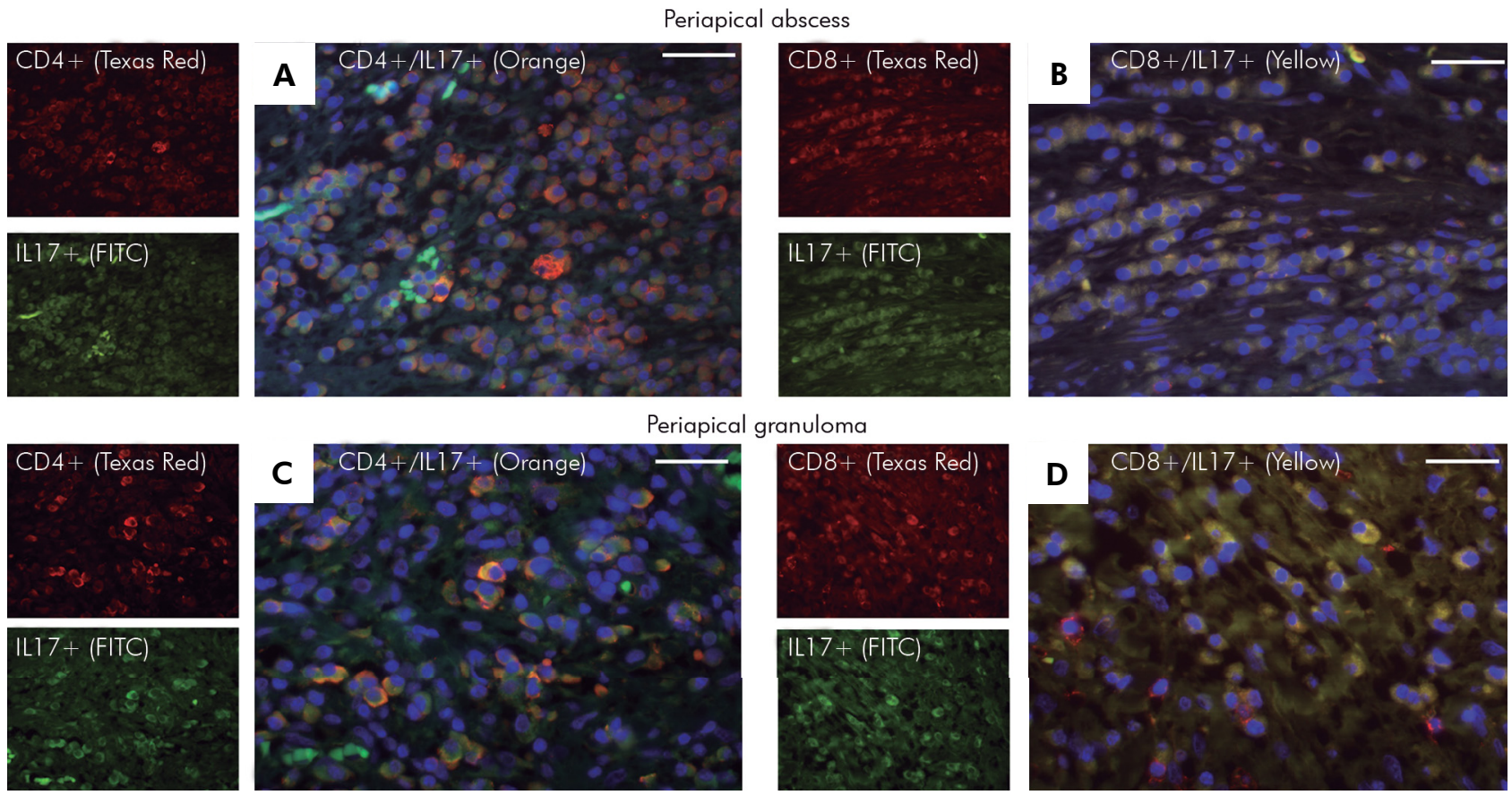

E Percentage of cells exhibiting double staining by immunofluorescence (CD4+/IL17+ and CD $8+/$ IL 17+)

\begin{tabular}{|c|c|c|c|}
\hline Lesions & CD8+/IL-17+ (\%) & $\mathrm{CD} 4+/ \mathrm{IL}-17+(\%)$ & $\begin{array}{l}\text { p-value for the comparison between } \\
\text { CD8/IL- } 17 \text { and CD } 4+/ / L-17^{*}\end{array}$ \\
\hline Periapical abscess & $\begin{array}{c}6.4( \pm 4.0) \\
5.2(3.4-10.6)\end{array}$ & $\begin{array}{c}16.9 \pm 8.9 \\
12.4(9.5-26.6)\end{array}$ & 0.025 \\
\hline Periapical granuloma & $\begin{array}{c}6.7 \pm 1.9 \\
7.5(4.9-8.0)\end{array}$ & $\begin{array}{c}10.6 \pm 3.9 \\
9.0(7.6-14.4)\end{array}$ & 0.047 \\
\hline $\mathrm{p}$-value for the comparison between abscess and granuloma & 0.2506 & 0.4624 & \\
\hline
\end{tabular}

\section{*Friedman's test.}

**Mann-Whitney's test.

Significant when $\mathrm{p}<0.05$.

Figure 4. Double immunolabeling of $\mathrm{CD}^{+} / \mathrm{IL}-17 \mathrm{~A}^{+}$and $\mathrm{CD} 8^{+} / \mathrm{IL}-17 \mathrm{~A}^{+}$detected by immunofluorescence in the periapical abscesses ( $A$ and B) and periapical granulomas $(C$ and D) $(400 \times$ original magnification, bar $50 \mu \mathrm{m})$. Orange color and yellow color represent double immunolabeling $\mathrm{CD}^{+} / \mathrm{IL}-17 \mathrm{~A}^{+}$and $\mathrm{CD}^{+} / \mathrm{IL}_{-} 17 \mathrm{~A}^{+}$, respectively. Fluorescence for each single marker is illustrated in small images. (E) Mean ( \pm standard deviation) and median (minimum and maximum values) percentages of cells exhibiting double immunostaining (CD4 $4^{+} / \mathrm{IL}_{-} 17 \mathrm{~A}^{+}$and $\left.\mathrm{CD} 8^{+} / \mathrm{IL}-17 \mathrm{~A}^{+}\right)$in the abscess and granuloma periapical lesions. 
in the majority of the lesions. A high percentage of elastase, IL-17A, and CD8 lymphocytes cells was observed. Elastase is one of the proteases present in the intracytoplasmatic azurophilic granules of the neutrophils, promoting the degradation of phagocytic microbial antigens in the intracellular compartment, or contributing to the destruction of these antigens in the extracellular environment. ${ }^{15}$ In periapical abscesses, the presence of elastase has been associated with the symptomatology of the lesions. ${ }^{16}$ Elastase immunolabeling identifies the polymorphonucleated inflammatory cells, mainly neutrophils. ${ }^{17}$ Past studies analyzing neutrophil infiltrate in pulpal and periapical abscesses reported that neutrophil recruitment in these lesions was more associated with the chemotaxis caused by bacterial toxins. ${ }^{18,19}$ Experimental models with induction of periapical lesions in animals have also demonstrated a participation of IL-17A in this process, mainly at initial phases of the lesion formation, a period when an intense influx of neutrophils is observed. ${ }^{20,21}$

In the present study, there was also high expression of $\mathrm{CD}^{+}$cells in the abscess cases. Participation of $\mathrm{CD}^{+}$cells in the innate immune response has been associated with non-antigen-specific cytokine release, controlling several types of bacterial infections. ${ }^{22}$ In pulpal infections by Streptococcus mutans, $\mathrm{CD} 8^{+}$ $\mathrm{T}$ lymphocytes are recruited more than $\mathrm{CD} 4^{+} \mathrm{T}$ lymphocytes, indicating that the type of antigen determines the $\mathrm{T}$ lymphocyte population in these infections. ${ }^{21}$ Moreover, IL-17A seems to induce the differentiation of $\mathrm{CD} 8^{+}$cells by increasing the release of IL-21 and to increase the cytotoxicity of these cells. ${ }^{23}$

In the granulomas, the percentage of CD4 labeling area was significantly higher than that of the other markers. Some studies have reported a high frequency of $\mathrm{CD} 4^{+}$cells in periapical granulomas, but without significant differences in comparison with $\mathrm{CD} 8^{+}$cells. ${ }^{4,24}$ The high proportion of $\mathrm{CD} 4^{+}$cells in granulomas has been associated with the initial process of granulomatous tissue formation, but great variance in cell populations in these lesions has frequently been reported. ${ }^{4}$

In the present study, the granulomas also exhibited a high percentage of elastase. Polymorphonucleated cells have also been found in granulomas, mainly in symptomatic lesions., ${ }^{3,40}$ Regarding IL-17A, all the granuloma lesions analyzed in the present study were positive for this cytokine, which is in agreement with other studies., ${ }^{4,10,11,12}$ The percentage of labeling area was, however, lower than that found for abscesses.

The main source of IL-17A in the abscesses and granulomas seems to be the $\mathrm{CD} 4^{+}$cells. Double immunolabeling revealed that the percentage of $\mathrm{CD}^{+} / \mathrm{IL}-17 \mathrm{~A}^{+}$cells is higher than that of $\mathrm{CD} 8^{+} / \mathrm{IL}^{-17 \mathrm{~A}^{+}}$ cells. This finding is in agreement with the majority of papers that discuss IL-17A and the Th17 phenotype. There is a consensus that there is a transformation of $\mathrm{CD}^{+}$cells into the Th17 phenotype, mainly in the presence of IL-23, IL- 6 , TGF- $\beta$, and transcription factors. ${ }^{8,25}$ However, the percentage of $\mathrm{CD}^{+} / \mathrm{IL}^{-17 \mathrm{~A}^{+}}$ cells was not negligible in both types of lesions (mean of $6.4 \%$ in the abscess cases and $6.7 \%$ in the granuloma cases), a fact that may suggest the participation of these cells in the Th17 response. The role of this double immunolabeling in acute and chronic periapical lesions must be better investigated.

It is important to mention that this study is limited with regard to the characterization of the Th17 response in the context of the apical periodontitis pathogenesis. We analyzed the anatomic distribution of a single cytokine, without additional analysis concerning its physiological role and the other cytokines. In addition, scarce information about the clinical evolution of the lesions, mainly regarding symptomatology and use of therapeutic tools, such as anti-inflammatory drugs, did not allow us to correlate the results with clinical variables.

\section{Conclusions}

Both the abscesses and the granulomas showed IL-17A immunolabeling, but in abscesses rich in neutrophils, this expression was higher. This fact suggests a role of this cytokine in the pathogenesis of the periapical lesions, particularly in the acute stages of the inflammatory process.

\section{Acknowledgements}

The authors would like to thank Coordenação de Aperfeiçoamento do Pessoal de Nível Superior - Capes, Brazil, for financial support. 


\section{References}

1. Schulz M, von Arx T, Altermatt HJ, Bosshardt D. Histology of periapical lesions obtained during apical surgery. J Endod. 2009;35(5):634-42. doi:10.1016/j.joen.2009.01.024

2. Shah AC, Leong KK, Lee MK, Allareddy V. Outcomes of hospitalizations attributed to periapical abscess from 2000 to 2008: a longitudinal trend analysis. J Endod. 2013;39(9):1104-10. doi:10.1016/j.joen.2013.04.042

3. Piattelli A, Artese L, Rosini S, Quaranta M, Musiani P. Immune cells in periapical granuloma: morphological and immunohistochemical characterization. J Endod. 1991;17(1):26-9. doi:10.1016/S0099-2399(07)80157-9

4. Čolić M, Gazivoda D, Vučević D, Vasilijić S, Rudolf R, Lukić A. Proinflammatory and immunoregulatory mechanisms in periapical lesions. Mol Immunol. 2009;47(1):101-13. doi:10.1016/j.molimm.2009.01.011

5. Jäger A, Kuchroo VK. Effector and regulatory T-cells in autoimmunity and tissue inflammation. Scand J Immunol. 2010;72(3):173-84. doi:10.1111/j.1365-3083.2010.02432.x

6. Gaffen SL, Hajishengallis G. A new inflammatory cytokine on the block: rethinking periodontal disease and the Th1/Th2 paradigm in the context of Th17 cells and IL-17. J Dent Res. 2008;87(9):817-28. doi:10.1177/154405910808700908

7. Korn T, Oukka M, Kuchroo V, Bettelli E. Th17 cells: effector $\mathrm{T}$ cells with inflammatory properties. Semin Immunol. 2007;19(6):362-71. doi:10.1016/j.smim.2007.10.007

8. Aujla SJ, Dubin PJ, Kolls JK. Th17 cells and mucosal host defense. Semin Immunol. 2007;19(6):377-82. doi:10.1016/j.smim.2007.10.009

9. Sadik CD, Kim ND, Luster AD. Neutrophils cascading their way to inflammation. Trends Immunol. 2011;32(10):452-60. doi:10.1016/j.it.2011.06.008

10. Čolić M, Vasilijić S, Gazivoda D, Vučević D, Marjanović M, Lukić A. Interleukin-17 plays a role in exacerbation of inflammation within chronic periapical lesions. Eur J Oral Sci. 2007;115(4):315-20. doi:10.1111/j.1600-0722.2007.00460.x

11. Marçal JR, Samuel RO, Fernandes D, Araujo MS, Napimoga $\mathrm{MH}$, Pereira AS, et al. T-helper cell type 17/regulatory T-cell immunoregulatory balance in human radicular cysts and periapical granulomas. J Endod. 2010;36(6):995-9. doi:10.1016/j.joen.2010.03.020

12. Henriques LC, Brito LC, Tavares WL, Vieira LQ, Ribeiro Sobrinho AP. Cytokine analysis in lesions refractory to endodontic treatment. J Endod. 2011;37(12):1659-62. doi:10.1016/j.joen.2011.08.007

13. Helps SC, Thornton E, Kleinig TJ, Manavis J, Vink R. Automatic non subjective estimation of antigen content visualized by immunohistochemistry using color deconvolution. Appl Immunohistochem Mol Morphol. 2012;20(1):82-90. doi:10.1097/PAI.0b013e31821fc8cd

14. Landini G. Color deconvolution. 2010 [cited 2015 Apr 24]. Available from: http://www.mecourse.com/landinig/ software/cdeconv/cdeconv.html

15. Korkmaz B, Horwitz MS, Jenne DE, Gauthier F. Neutrophil elastase, proteinase 3, and cathepsin G as therapeutic targets in human diseases. Pharmacol Rev. 2010;62(4):726-59. doi:10.1124/pr.110.002733

16. Alptekin NO, Ari H, Ataoglu T, Haliloglu S, Alptekin T, Serpek B. Neutrophil elastase levels in periapical exudates of symptomatic and asymptomatic teeth. J Endod. 2005;31(5):350-3. doi:10.1097/01.don.0000140567.25382.cd

17. Wiedow O, Muhle K, Streit V, Kameyoshi Y. Human eosinophils lack human leukocyte elastase. Biochim Biophys Acta. 1996;1315(3):185-7. doi:10.1016/0925-4439(95)00121-2

18. Hahn CL, Liewehr FR. Update on the adaptive immune responses of the dental pulp. J Endod. 2007;33(7):773-81. doi:10.1016/j.joen.2007.01.002

19. Adamkiewicz VW, Pekovic DD. Experimental pulpal Arthus allergy. Oral Surg Oral Med Oral Pathol. 1980;50(5):450-6. doi:10.1016/S0030-4220(80)80014-4

20. Xiong H, Wei L, Peng B. Immunohistochemical localization of IL-17 in induced rat periapical lesions. J Endod. 2009;35(2):216-20. doi:10.1016/j.joen.2008.10.022

21. Oseko F, Yamamoto T, Akamatsu Y, Kanamura N, Iwakura Y, Imanishi J, et al. IL-17 is involved in bone resorption in mouse periapical lesions. Microbiol Immunol. 2009;53(5):287-94. doi:10.1111/j.1348-0421.2009.00123.x

22. Berg RE, Forman J. The role of CD8 T cells in innate immunity and in antigen non-specific protection. Curr Opin Immunol. 2006;18(3):338-43. doi:10.1016/j.coi.2006.03.010

23. Duan MC, Huang Y, Zhong XN, Tang HJ. Th17 cell enhances CD8 T-cell cytotoxicity via IL-21 production in emphysema mice. Mediators Inflamm. 2012;2012:898053. doi:10.1155/2012/898053

24. Walker KF, Lappin DF, Takahashi K, Hope J, Macdonald DG, Kinane DF. Cytokine expression in periapical granulation tissue as assessed by immunohistochemistry. Eur J Oral Sci. 2000;108(3):195-201. doi:10.1034/j.1600-0722.2000.108003195.x

25. Weaver CT, Hatton RD, Mangan PR, Harrington LE. IL-17 Family cytokines and the expanding diversity of effector T cell lineages. Annu Rev Immunol. 2007;25(1):821-52. doi:10.1146/annurev.immunol.25.022106.141557 